\title{
Gamification Framework for E-Learning Systems in Higher Education
}

\author{
Andrija Bernik
}

\begin{abstract}
This paper explains the concept of gamification, lists the current models according to which educational e-courses can be designed, and proposes a conceptual eRIOOS model aimed at higher education. The aim of the research as well as the purpose of creating a conceptual model of gamification is to standardize the elements of computer games that can be used in educational e-courses at higher education institutions. In the preparation of this research, the emphasis was placed on the invention and analysis of professional and scientific literature for creating a conceptual model. The model contains a logical representation of two levels of complexity. Three separate e-courses have been created in different courses within the two University institutions, which serve as a tool to check the correctness of the conceptual eRIOOS model. The result of the research is a confirmed conceptual model that is suitable for creating Moodle e-courses of IT teaching orientation in higher education institutions.
\end{abstract}

Keywords: e-course; eRIOOS; gamification; model; Moodle; University

\section{RELATED WORK}

In this part of the paper are listed the researchers and their model proposals for the development of gamified systems that can be used for educational purposes. [1] in their paper present a Dynamical Model for Gamification of Learning (DMGL). [1] refer to [2] who founded the MDA model (Mechanics, Dynamics, Aesthetics). The MDA model is based on elements of mechanics, dynamics, and aesthetics. [3] complemented the MDA model with challenges, imagination, control, and curiosity. The result of DMGL is a system that is very different from traditional teaching. [1] state that educational efficiency in the case of gamification is significantly lower in relation to traditional teaching, but this indicator is valid only in the initial stages of teaching. It is concluded that time is needed for getting used to and adapting, followed by a rapid increase and surpassing the effectiveness of traditional learning. [4] present in their research a model for gamified activities. The model includes some of the key elements such as content, tasks, levels, feedback, top lists, and group preferences. In addition to the above-mentioned elements, it is suggested to use rewards and penalties, time-limited tasks, and auxiliary units that are in the function of scripts. The model presents a series of links and guidelines in the form of a kind of simple activity diagram. The model is a theoretical proposal on how to create a functional unit focused on teaching in higher education institutions. [4] mention this as the next step in their research. [5] in his research lists the steps that should be taken into account when planning and implementing gamification in business systems: Identifying organization goals, Identifying the main objective of the gamification system, Identifying users, Identifying content, Designing and selecting elements of computer games, Defining measuring instruments, Defining communication methods, Monitoring efficiency, and system improvement. The same principles could be applied to education systems. [6] describe a model called Octalysis developed by Y. Chou [7, 8, 9]. The Octalysis model represents a systematic model that puts the visualized elements of a certain system into a visual interrelation. The model is based on the assumption that almost any game or game-based system is fun because it affects the basic motivational traits of the user. The result is the encouragement of pre-planned activities. The Octalysis model is based on eight motivational drivers, which, according to Chou, are arranged in an octagonal shape as shown in Fig. 1 of this paper. The elements of the Octalysis model that are in the right part of Fig. 1 represent a stimulus for creativity, self-expression, and sociability. These elements are related to intrinsic motivation, as opposed to the elements on the left side, which relate to extrinsic motivation. The elements of the left side are associated with goals, rewards, goods that can be earned or won. The elements at the top of the system are considered to be positive motivators that encourage the improvement of knowledge and skills through meaning and various incentives. The elements at the bottom of the system are considered negative motivators that encourage bad emotion and should be minimized when planning and implementing the system. [10] and [11] state a division that focuses on designing a gamification educational course. The division is simplified and consists of five steps: Understanding the content and users - the first step in which the administrator or teacher of the gamification system is introduced to possible problem situations depending on the teaching units and target groups of e-course participants.

Defining goals - refers to any set of elements that can improve knowledge and motivation or encourage a change in the behavior of e-course participants. Goals are closely related to learning outcomes which are approached as challenges that contribute to a meaningful unit. Structuring the experience - the system is analyzed in parts with the aim of identifying which units are more difficult for e-course participants, and a special user incentive is planned in these units. The incentive has a positive effect on the motivation of e-course participants and the continuation of learning through points, certificates, virtual currencies, or other incentive elements.

Resource identification - resources mean anything that is measurable, e.g. points, passed knowledge tests, or time. In this phase, the rules and feedback related to the activities of e-course participants are defined. Defining the elements - the last step is to connect the rules and resources with regard to 
the e-course participants and the teaching units. The selected gamified elements should be clear enough and accepted by the e-course participants so as not to create the opposite effect when using the system. Some of the more used elements from computer games are: avatar, interface personalization, bonus materials, forming of teams, feedback, rewards, points, virtual currencies and stores, motivational story, transparency of system points, etc. [12] proposes a model for gamified system development, within a book called: "For the Win: How Game Thinking Can Revolutionize Your Business" in six interrelated steps. The model he proposed is called the 6D model. It includes six words with the first letter $\mathrm{D}$ and hence the name: define business objectives, delineate target behaviors, describe your players, devise activity loops, don't forget the fun, deploy appropriate tools.

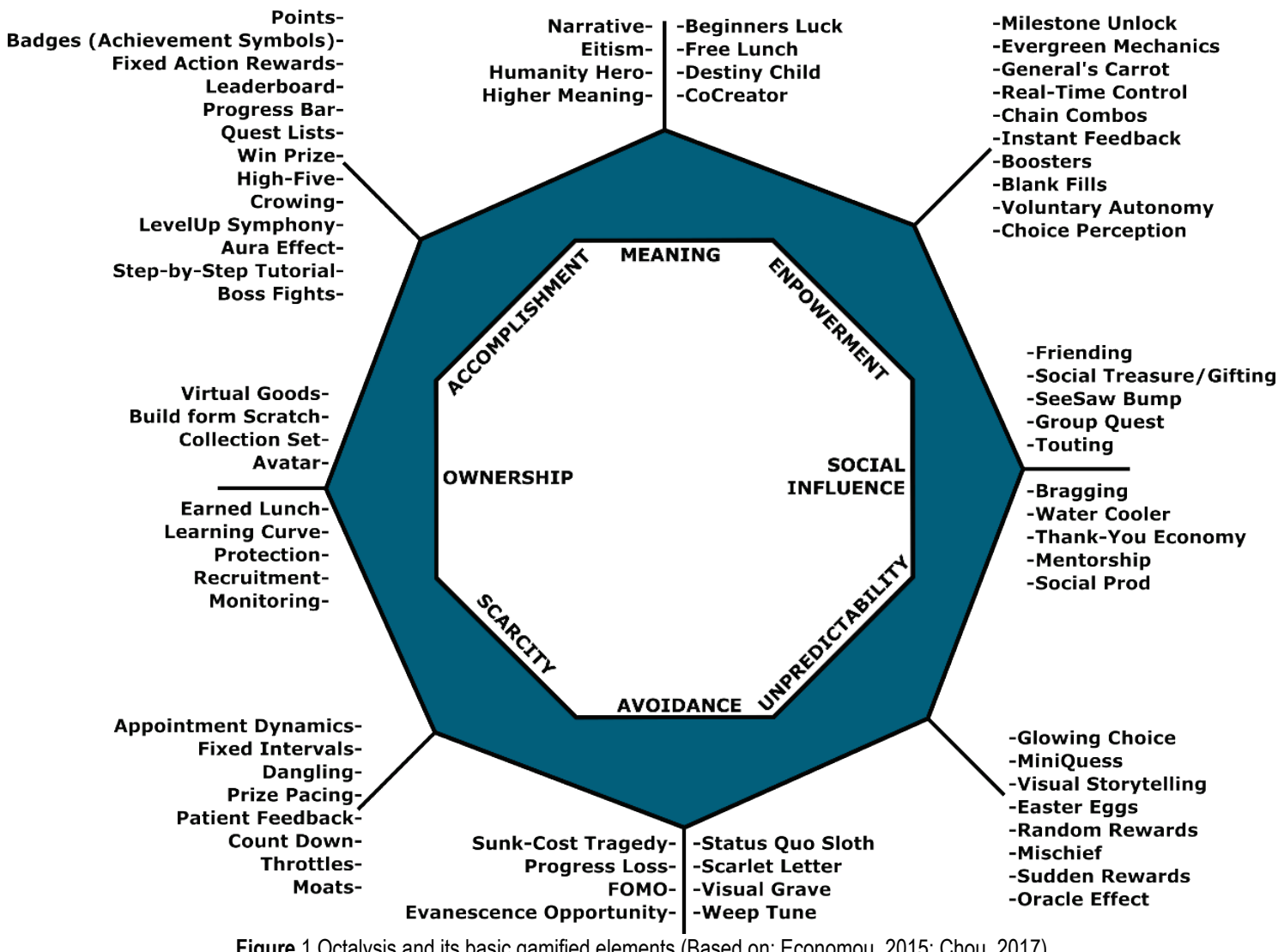

Figure 1 Octalysis and its basic gamified elements (Based on: Economou, 2015; Chou, 2017)

The mentioned gamification model includes a component of emotion that is based on fun, play, and user experience, as well as a sustainable system in which the result and activity of the user are measurable, all in order to achieve predetermined goals. [13] adds that the entire 6D model consists of guidelines on how to use modern technological advances (computer games elements) in specific situations. Schönen points out that success can only be achieved with the correct selection and application of computer game elements, explaining that the first five elements of the proposed Werbach 6D model consist of planning activities and describing the target group of subjects.

\section{RESEARCH METHODOLOGY}

In this part of the paper are explained the procedures used in planning and conducting the research, and listed the subjects who voluntarily participated in the research. The research was conducted through two phases which are listed below. The first phase - Theoretical research - the implementation of research begins with the analysis and research of professional and scientific literature in order to find specific guidelines for creating a conceptual model focused on research topics. A list is created of gamified elements for the Moodle system which are listed below.

The second phase - Development of a conceptual model - a conceptual gamified eRIOOS model is developed. The conceptual eRIOOS model is a condition for creating an experimental, gamified system on the basis of which scientific research is carried out. The conceptual model is aimed at improving and applying computer games elements in the online education system.

For the purposes of the research work, a computer server was used on which separate Moodle e-courses were installed, which were supplemented with computer games elements. The installed version of the Moodle system at the time of conducting research supports 1137 external add-ons. All 1137 add-ons are, before being selected and implemented in a gamified Moodle system on a separate server, viewed and compared with the mechanics and dynamics of computer games discussed in the previous chapter. Some of the additions are listed below [14]: Simplified graphical 
interface, Dynamic graphical interface, Story as an introduction to the e-course, Epic meaning, Visual presentation of all obligations, Tasks and challenges, Collecting points, Progress within the e-course, Synchronous communication Chat, Asynchronous communication Forum,

Nonlinear use of teaching materials, Joint collaboration, Discovering the system and teaching materials,

Surprise elements within the e-course, Conditional access to teaching materials, Countdown, Simplified graphical interface, Dynamic graphical interface,

Story as an introduction to the e-course, Epic meaning, Visual presentation of all obligations, Tasks and challenges, Collecting points,

Progress within the e-course. The accessories included in the gamified system influence the mechanics of computer games and the visual impression of the system in order to create an interesting virtual space and the preconditions for a positive impact on student motivation.

\section{PROPOSAL AND IMPLEMENTATION OF THE CONCEPTUAL SOLUTION}

An analysis of the subjects was made and the selection of subjects was carried out in accordance with the principles of scientific research. The time of the experiment and the intervals in which the subjects were acquainted with the obligations and possibilities of the research were chosen. Subjects were not told anything that could impair correctness in subsequent measurements. The time of conducting the research also defined the teaching unit, considering how the research was conducted during the academic year. For the selected teaching unit, it was necessary to define the teaching contents for classical and experimental e-courses in all three research. The classic e-course contains teaching materials, knowledge testing, and feedback on success, which is visible to the e-course participant after the knowledge test. Teaching materials are in most cases static and factually oriented without giving insight into the wider practical application. At the end of the teaching process, the student is expected to have knowledge, regardless of the motivation or feeling that the student had while using the classic e-course. The benefit of such an e-course is the transfer of information and the availability of teaching content at all times.

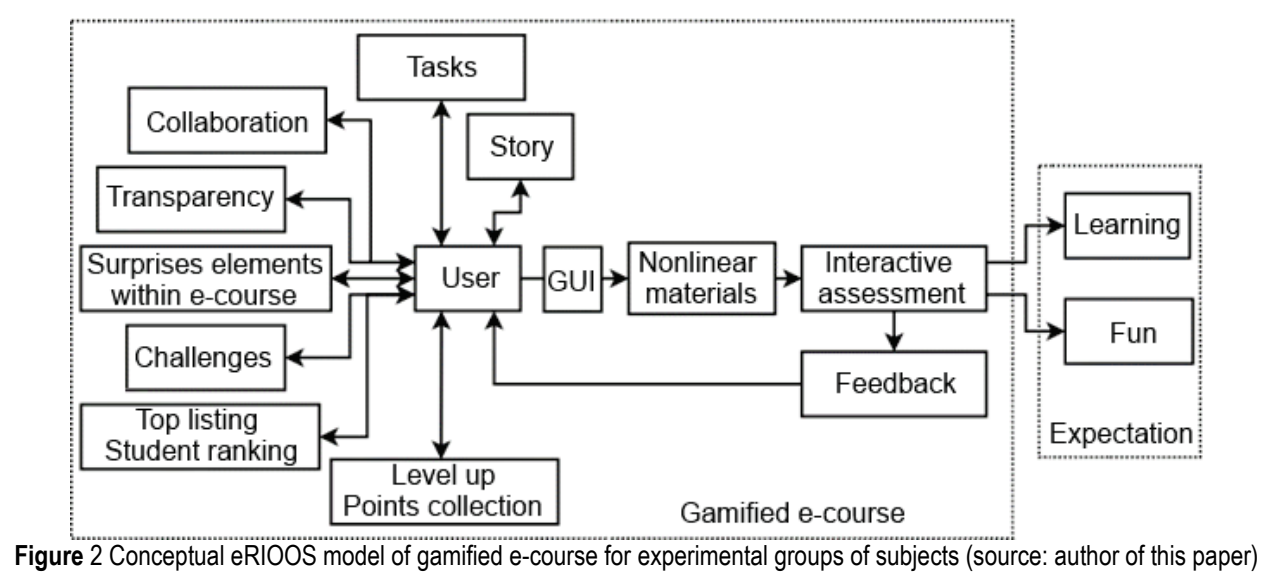

Fig. 2 shows the gamified e-course for the experimental groups of subjects that will be used in the development of gamified solutions for the e-courses of this research. It can be noticed that the student is deliberately surrounded by gamified elements, i.e. elements of computer games that are included in the e-course in order to motivate and entertain the participants of the e-course. The student uses a more intuitive user interface that is clearer, visually richer, and easier to manage and use. Before starting to use the teaching materials, the student is introduced to the meaning of the e-course through a story and practical examples, which achieves a deeper meaning and a positive impact on intrinsic motivation. At the time of using the e-course, the student can approach solving problem tasks related to the teaching unit or accompanying bonus teaching or non-teaching content that reveals hidden elements or parts of the e-learning system. Within the e-course, transparency is ensured in terms of course obligations, as well as in terms of the achievements of other students. The student has at its disposal the interaction with other users of the system (teachers and students) whether it is a competition or mutual cooperation. The result of student activities is visible through the Top lists, but also through other indicators such as the number of badges, the number of points, and the level at which the student is. Progress is provided in terms of system levels and the association of certain symbols to the participant. Expectations from students are knowledge and higher motivation to learn, which are ensured by greater freedom of choice of access to teaching materials, and more visual or auditory guidance and feedback information on the performance of student activities. E-learning system designed in this way should allow students to achieve a sense of comfort, fun, and autonomy over their learning process, and achieve a state of the flow in which learning is fastest.

The eRIOOS model shows the use of a number of computer games elements that aim to achieve greater flexibility and dynamism of e-learning systems. Regardless of the e-learning platform, the student should be provided 
with a modern graphical interface that supports simple menu animations, background music, and similar multimedia elements that can evoke the ambiance or moment in the story. The mentioned functionality is related to creating a simpler and more intuitive user atmosphere that provides the student with a feeling of comfort and relaxation. Each teaching activity should start as a practical task or problem situation in which the student is introduced to the possibilities of the e-course as well as the possible results that are the consequence of the student's activities. Given how the eRIOOS model is aimed at students of higher education institutions, the story, i.e. the problem situation should follow the generally known, contemporary situations in the field of e-course. The story should put the student in the role of researcher, collector, winner, or socialite, and guide him through the e-course with the aim of activating intrinsic motivation.

The story can be related to the planned knowledge tests, and according to the results of the participants, it can be further upgraded or changed depending on the achievements of the group. The mentioned is not easy to achieve, and teachers are expected to harmonize teaching content and stories with real events in the business world. Harmonizing teaching content and story with real events leads to achieving a higher goal than simply collecting points and learning for routine knowledge tests. This ensures the so-called. an epic meaning that is lacking in the classic e-course as well as in traditional education.

In addition to the teaching materials that are the foundation of the e-learning system, the aim is to provide as many meaningful knowledge tests as possible so that students question the knowledge of teaching topics, and think about certain problematic situations. Tasks and challenges should be related to the points, badges, or certificates awarded to the student depending on the difficulty of the task or the scope of the challenge. As one goes through the system, the tasks and challenges should become increasingly difficult thus ensuring a virtual passage through the teaching units. Points, badges, certificates, or awards in other forms should be publicly visible to all participants, thus ensuring the transparency of grading as well as the recognition of knowledge among e-course participants. In computer games, there are often situations when a player has to face a big obstacle in the form of the main enemy (Boss Enemy). In the e-course, such an element can be achieved through a story in which the student is put in a stressful situation where on the one hand there is a time limit to solve the problem situation, and on the other hand, there is an opponent in the form of artificial intelligence or the teacher himself. An example of this can be a case in which an individual or a team of several participants, and even a whole group of participants, come to a situation where they need to "hack" the exit or entrance to a certain space that is extremely important (according to the story presented at the beginning of the e-course). On the one side are the participants of the e-course, while on the other side is the "opponent" (program or teacher) depending on the level of gamification of the e-learning system. An epic meaning can easily be achieved by such an example. In this case, the synergy and motivation of users to win is achieved, which in a positive way affects the direction and development of the story that supports the educational process in the e-learning system. A similar effect is also achieved with educational games that are already available in e-learning systems but at a slightly lower level of abstraction. It is important to provide multiple access to interactive repetition and the above knowledge tests so that students can master certain teaching units as well as improve existing knowledge.

According to $[15,16]$ as well as according to other authors $[17,18]$ there are the following types of players: researcher, collector, winner, and socialite. Players rarely belong to only one of these profiles, it is more common where the player has the characteristics of all four types of players where each element is developed to some extent, which is why it is necessary to provide the ability to personalize elearning systems.

The simplest way is to enable the use of profile pictures followed by personal information and social statuses, which ensures the sharing of interesting or student-important information, as well as the sharing of status about certain achievements. This is visible within social networks that ensure the sharing of status, social interests, and personal information with other users of the system. The e-learning system should ensure that users are connected as well as sharing their achievements and status at a given time. Supporting information can also be available to all e-course participants if the student wants to share it via his personal status or through synchronous (chat) or asynchronous communication systems (forum or personal information). Synchronous and asynchronous communication enable the dissemination of information between all participants in the e-course, where teachers are required to take on the role of "administrator of communication messages". On the one hand, it is necessary to ensure autonomy in terms of communication between users, while on the other hand, it is necessary to direct the flow of data and written information in the direction of desirable teaching activities. With the assumption that the group of participants is serious enough, it is enough to set notes and guidelines for communication at a certain time and follow the course of the conversation.

It is useful to set time limits for a particular teaching topic to ensure emphasis on a particular topic. It is also advisable to provide virtual meetings in which students are discussed about their achievements and to announce future events and introduce students to the benefits if the task is successfully completed. In this way, it is possible to further encourage students for greater joint cooperation and engagement, as well as to provide a project approach to the teaching unit or problem task that can be seen in business environments.

Students come to the e-course with different prior knowledge as well as with different ambitions. The speed at which a student can go through the teaching materials should not be limiting, however, it is up to the teacher to decide whether to provide certain obstacles in the system or not. Also, it is not excluded that students master the complete teaching unit before the end of the semester, and they should be provided with bonus materials and additional activity that 
would ensure the need for advanced knowledge. It is not good to slow down such individuals to the speed of the group average because they lose interest in the topic as well as the desire to further participate in teaching activities. If the student is excellent, he needs to be provided with extracurricular or bonus materials that will not be visible or accessible to other participants. All participants have certain teaching and non-teaching materials at their disposal. When creating an e-course, the teacher determines the time periods in which unannounced changes will occur in the system in terms of visual surprise or in terms of new, until then hidden teaching or non-teaching materials. These elements are surprise elements that are planned to cheer up the participants of the system, and at the same time motivate them for further teaching or non-teaching activities.
Feedback on the activities carried out by the student in the e-course as well as other feedback related to the status of progress, the status of completion of teaching obligations in the e-course, as well as a visual presentation of points and other positive achievements that the student accomplished over time are an important element of the gamified system. E-learning platforms, such as Moodle, provide a certain level of feedback on the success of student activities that encourage the student to further improve and go through teaching and non-teaching materials. Given that additional elements from computer games are introduced into the elearning system, special attention should be paid to providing feedback also for these elements if they are important for motivating or work of students.

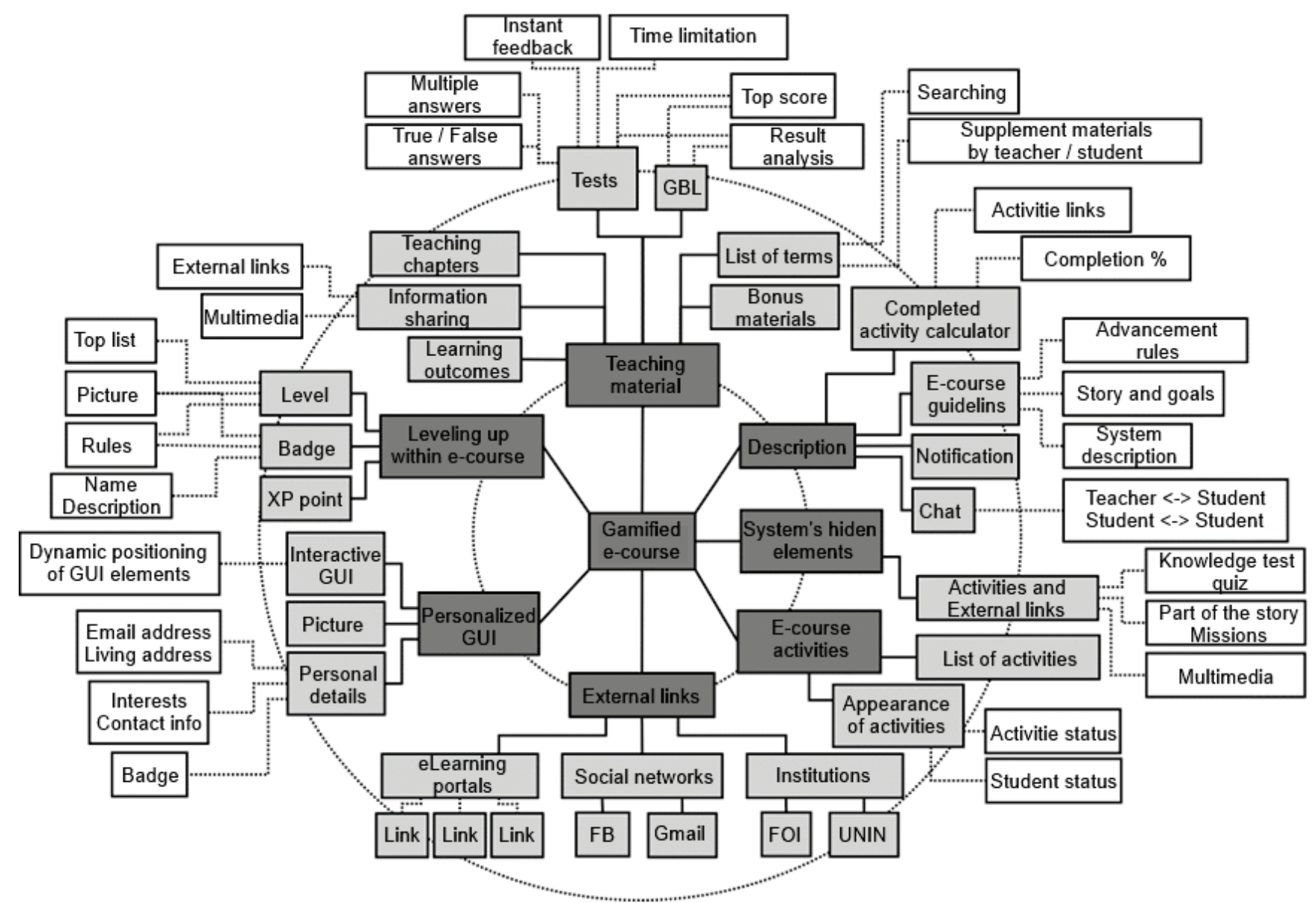

Figure 3 Conceptual solution created according to the eRIOOS model (source: author of this paper)

The eRIOOS model is oriented towards the student with teaching or non-teaching activities that are available to the student within the education system. The eRIOOS model does not bring significant changes for the teacher in the form of facilitating teaching or monitoring the teaching process. On the contrary, the teacher will have more obligations in the planning and initial creation phase of the e-course if he wants to provide all the possibilities recommended by the model. The conceptual model of the gamified e-course, shown in Fig. 2, also serves as a basis for the development of a conceptual solution created for research within this paper.
The developed conceptual solution can be found in Fig. 3 and contains seven main units (Teaching unit, System description, Hidden system elements, Course activities, External links, GUI personalization, and Progress within the course). The gamified elements presented in the e-courses for the experimental group of subjects in the first and second main research are marked with white color. Each of the seven units is explained after the picture of the conceptual solution in the continuation of the paper. Fig. 3 shows an example of the computer games elements included in the eRIOOS model 
and how the elements are connected and organized within the platform intended for e-learning.

The conceptual solution from Fig. 3 makes the structure to which it is necessary to add teaching materials and contents. The student directly interacts with the eight elements of computer games and indirectly with feedback, which has a big impact on his experience of the educational environment. If the system is designed correctly, the student creates a sense of comfort that can lead to a state of flow in which the learning process is optimal. The goal to be achieved was to ensure the state of the flow in which the student learns the fastest while reducing the feeling of fatigue and stress that occurs in the case of a uniformly structured ecourse.

\section{MODEL TESTING AND VALIDATION}

The effect of the conceptual model, as well as the verification of whether the application of computer game elements enabled the achievement of higher results in the knowledge test in the experimental group of subjects was conducted in three independent research (on three separate ecourses). To achieve the mentioned, based on the conceptual eRIOOS model, gamified Moodle e-courses were created for experimental groups of subjects. In parallel with this, classic versions of the Moodle e-course have been developed intended for control groups of subjects. Gamified e-courses for each research were created again because e-courses are conducted in different courses (North University, Faculty of Organization and Informatics) and on different servers (unin.hr, foi.hr). Teaching materials are adapted for the purposes of this research and do not differ from each other in their content. Subjects who participated in the research $(N=$ $309)$ voluntarily agreed to research activities and actively participated in the validation of the conceptual model. Validation, as well as testing of the conceptual model, is carried out according to pre-agreed rules that must be followed with each group of subjects in each of the selected courses.

In the first step, the subjects were exposed to a pre-test based on which the participants were divided into groups. The second step was to check that the groups were statistically equal. The statistical significance is checked and a conclusion is made on satisfying the initial conditions of the research. In the third step, the subjects use one of the assigned e-courses (experimental or control) within their groups and are exposed to a post-test, i.e. a written test of knowledge that tests the knowledge from the teaching contents used in the experiment. Depending on the average result from the posttest knowledge test, it is concluded based on t-test analysis, with the possibility of an error of $1 \%$ or $5 \%$, that there is or is not a statistically significant difference between these subjects. Each research has identical steps and at the end of each research, conclusions were made about the success of the measurement.

For the purposes of this paper, a part of previously published research in $[14,19,20]$ is cited.

The conceptual model was tested on two main hypotheses that were tested through the experimental and control group on a total of 309 subjects. Testing was conducted three times on three different courses, academic years, and 2 higher education institutions. The hypotheses are:

H1. An e-course designed with the application of computer game elements has a positive effect on the interest of the participants in that course in relation to the course of the same educational content but without the presence of computer game elements.

H2. An e-course designed with the application of computer game elements enables the achievement of better results for students compared to traditional approaches to elearning, having in mind the level of acquired knowledge from certain teaching content.

The indicators obtained by the analysis are as follows:

- In the first series of measurements, student activity was almost 65 times higher in relation to the control group of subjects, and the average number of points of the experimental group in relation to the control group was higher by $36.55 \%$.

- In the second series of measurements, the difference in activity was almost 5 times larger in favor of the experimental group of subjects, and the average number of points of the experimental group compared to the control group was higher by $15.46 \%$.

- In the third series of measurements, the difference in activity was 13 times greater in favor of the experimental group of subjects and the average number of points of the experimental group compared to the control group was higher by $33.23 \%$.

\section{CONCLUSION}

Based on the gamified elements of the Octalysis system, and the found guidelines from the literature, the author of this research develops a conceptual gamified eRIOOS model based on which it is possible to develop a complete gamified e-course intended for higher education. Based on the eRIOOS model, suitable elements of computer games are included in the Moodle platform, with a positive impact on the student's behavior and interest in the teaching and nonteaching elements of the e-course.

The conceptual eRIOOS model enables the student: more intuitive Graphical User Interface, achieving deeper meaning through story and practical examples, solving problems related to teaching units, solving problems related to the accompanying bonus content, interaction with other system users (teachers and students), transparency regarding the course obligations, transparency regarding the achievements of other course participants, revealing hidden elements or parts of the system, competition with other system users and visible order in the form of Top list, progress in the form of system levels and joining symbols to the student, greater freedom to choose access to teaching materials, a greater amount of visual or auditory guidance about the learning process, achieving a sense of comfort, fun, and autonomy over the learning process, achieving a state of flow in which learning is fastest. 
The conceptual model at the theoretical level has nine additions (advancement, top list, competition, hidden entertainment additions, transparency, interaction, story, challenges, feedback), extended at the implementation level to a total of 24 elements that contributed to the creation of the gamified system. The eRIOOS conceptual model is the basis for the gamified e-course, which was used in the first series of research within the North University $(\mathrm{N}=55)$ as well as the second and third series of research conducted at the Faculty of Organization and Informatics $(\mathrm{N}=254)$. The test results are briefly presented at the end of Chapter 4 of this paper and indicate that all experimental groups of subjects who used the gamified Moodle system have statistically significantly better results. Note that the only difference between the control and experimental groups was in the layout of the e-course. Everything else is identical (order and amount of teaching materials). In addition, it can be seen that the group that used the gamified e-course used the e-learning system much more, which is another indicator that is in favor of the eRIOOS system. The conceptual model has been empirically and theoretically confirmed because it is based on the research of other scientists and respect for their conclusions regarding the use of elements of computer games within the educational system.

Further application of this model is possible in the form of creating e-courses intended for higher education. The field of application is not limited only to IT teaching subjects with regard to the used elements of computer games and the theory of flow according to which the prerequisites for achieving the state of the flow for system users are met.

\section{REFERENCES}

[1] Kim, J. T. \& Lee, W. (2013). Dynamical model for gamification of learning (DMGL). Multimed Tools Appl, 74, 8483-8493 (2015). https://doi.org/10.1007/s11042-013-1612-8

[2] Deterding, S., Dixon, D., Khaled, R., \& Nacke, L. (2011). From game design elements to gamefulness: Defining gamification. $15^{\text {th }}$ International Academic MindTrek Conference: Envisioning Future Media Environments, USA, 9-15. https://doi.org/10.1145/2181037.2181040

[3] Zichermann, G. \& Cunningham, C. (2011). Gamification by Design: Implementing Game Mechanics in Web and Mobile Apps, O'Reilly Media, Inc.

[4] Carvalho, A. A., Araújo, I., \& Zagalo, N. (2014). A Framework for Gamified Activities Based On Mobile Games Played by Portuguese University Students. International Conferences on Educational Technologies and Sustainability 2014, Technology and Education.

[5] Ergle, D. (2015). AirBaltic Case Based Analysis of Potential for Improving Employee Engagement Levels in Latvia through Gamification. Scientific Conference on Economics and Entrepreneurship. https://doi.org/10.1515/eb-2016-0007

[6] Economou, D., Doumanis, I., Pedersen, F., Kathrani, P., Mentzelopoulos, M., \& Bouki, V. (2015). Evaluation of a dynamic role-playing platform for simulations based on Octalysis gamification framework. The $11^{\text {th }}$ International Conference on Intelligent Environments. https://doi.org/10.1109/IMCTL.2014.7011138
[7] Chou, Y. (2019). Octalysis: Complete Gamification Framework. https://yukaichou.com/gamification-examples/ Octalysis-complete-gamification-framework/ (Accessed: 23.07.2020.)

[8] Chou, Y. (2019). Top 10 education gamification examples. https://www.yukaichou.com/gamification-examples/top-10education-gamification-examples (Accessed: 23.07.2020.)

[9] Chou, Y. (2015). Why is gamification not included in Gartner's 2015 Hype Cycle? https://www.quora.com/Why-isgamification-not-icluded-in-Gartners-2015-Hype-Cycle (Accessed: 23.07.2020)

[10] Huang, Y., Backman, S. J., Backman, K. F., \& Moore, D. (2013). Exploring user acceptance of 3D virtual worlds in travel and tourism marketing. Tourism Management, 36, 490501. https://doi.org/10.1016/j.tourman.2012.09.009

[11] Hendriks, M. (2015). Gaming the system: Making personalized learning fun. Master Thesis Computer Science, University Radboud Nijmegen.

[12] Werbach, K. \& Hunter, D. (2012). For the Win: How Game Thinking Can Revolutionize Your Business. Wharton Digital Press, University Pennsylvania, Philadelphia.

[13] Schönen, R. (2014). Gamification in Change Management processes: An empirical research by means of qualitative methods to analyze relevance, implications and selected use cases. Bachelor Thesis, University of Applied Sciences Munich.

[14] Bernik, A., Radošević, D., \& Bubaš, G. (2017). Introducing Gamification into e-Learning University Courses. The $40^{\text {th }}$ Jubilee International Convention - Mipro 2017, Croatia. https://doi.org/10.23919/MIPRO.2017.7973515

[15] Bartle, A. R. (1985). MUD Advanced Project Report, an internal memorandum (CSM-73), Department of Computer Science's series, University of Essex, UK.

[16] Bartle, A. R. (1996). Players Who Suit MUDs, a refereed paper. Journal of MUD Research, 1(1).

[17] de Vitte, F., Tabak, M., Dekker, M., \& Vollenbroek-Hutten, M. (2015). Increasing Motivation in eHealth Through Gamification, University of Twente.

[18] Gil, B. \& Cantador, I. (2015). On The Development of Gamified Activities in The Classroom. II. International Workshop on Gamification in Education: gEducation 2015, Spain.

[19] Bernik, A., Radošević, D., \& Bubaš, G. (2019). Achievements and Usage of Learning Materials in Computer Science Hybrid Courses. Journal of Computer Sciences, 15(3), 247. https://doi.org/10.3844/jcssp.2019.489.498

[20] Bernik, A., Radošević, D., \& Strmečki, D. (2017). Research on efficiency of applying gamified design into University's ecourses: 3D modeling and programming. Journal of computer science, 13(12), 718-727. https://doi.org/10.3844/jcssp.2017.718.727

\author{
Author's contacts: \\ Andrija Bernik, PhD, Assistant Professor \\ University North, \\ 104. brigade 1, 42000 Varazdin, Croatia \\ andrija.bernik@unin.hr
}

